\title{
Psychological, behavioural, and social adjustment in children and adolescents with juvenile chronic arthritis
}

A C J Huygen, W Kuis, G Sinnema

\begin{abstract}
Objective-To assess the psychological, behavioural and social adjustment of children (7-11 years) and adolescents (12-16 years) with juvenile chronic arthritis (JCA). Higher rates of maladjustment were expected to be found in these patients.
\end{abstract}

Methods-Self report questionnaires were used within the context of personal interviews. Family functioning and social support were studied as well. Forty seven patients with JCA, 52 healthy peers and their respective parents participated in the study.

Results-Self esteem, perceived competence and body image in patients with JCA were as positive as they were in healthy participants. There were no differences between ill and healthy youngsters with respect to the incidence of psychopathology. Patients with JCA, in general, perceived themselves as socially competent, but they seemed to have somewhat less opportunity or energy to participate in social activities. Children with JCA showed a high level of aspiration to cope with social expectations. This aspiration seemed to be even stronger in case the disease caused more strains, for example, in periods of inflammation and in the systemic onset type. The high level of social adjustment in children with JCA seemed to be supported by highly cohesive family structures. Generally, adolescents with JCA experienced much social support.

Paediatric Psychology, University Medical Centre Utrecht, Wilhelmina Children's Hospital, Utrecht, the Netherlands

A C J Huygen

G Sinnema

Department of

Paediatric

Rheumatology,

University Medical

Centre Utrecht,

Wilhelmina Children's

Hospital

W Kuis

Correspondence to:

Dr Sinnema, University

Medical Centre Utrecht, PO

Box 85090, KA.00.004.0,

3508 AB Utrecht, the

Netherlands

Acepted for publication

15 December 1999
Conclusions-In contrast with our expectation, children and adolescents with JCA seemeed to cope quite well with the psychological and social consequences of their long term condition. For future studies, it is hypothesised that the high levels of adaptation might imply an enduring psychological strain, which is reflected in an altered function of the autonomic nervous system.

(Ann Rheum Dis 2000;59:276-282)

Juvenile chronic arthritis (JCA) is a childhood disease with a great impact on normal development and daily life functioning. Disease symptoms, physical disabilities and treatment modalities, such as physical therapy, medication and surgery can place a heavy strain on the adaptational capacities of the child and the family. Eventually cognitive, emotional, behavioural, social or family problems may arise. ${ }^{1-4}$
Behavioural research on the impact of a chronic disease on children shows conflicting results. On the one hand, epidemiological surveys show that chronically ill children are more at risk for psychiatric problems, social isolation and school problems than are healthy children of the same age. ${ }^{56}$ On the other hand, some clinical studies show no differences compared with healthy children, ${ }^{7}$ or even show superior functioning in chronically ill children. ${ }^{8}$

The conflicting outcomes in the various studies can be partly explained by the use of different assessment methods. For example, Vandvik $^{7}$ using the Child Behaviour Check List, ${ }^{9}$ - a written self report questionnairefound no differences in the frequency of problem behaviour between patients with JCA and their healthy siblings. Application of the Child Assessment Schedule, ${ }^{10}$ - an interview-to the same group, however, showed that $50 \%$ of the patients with JCA could be categorised as having a psychiatric disturbance. Thus, the two instruments, both designed to measure psychiatric characteristics, show significant differences within the same group. Furthermore, behavioural research covers quite different developmental and behavioural domains with a great variety of instruments to measure these domains. Hence, it is difficult to compare the results from the different studies. These methodological inconsistencies partly explain the discrepant results of studies on the impact of a chronic illness on the psychological and social development of the child, ${ }^{11-13}$ the influence of the child's cognition and experiences on the course of the illness, ${ }^{14}$ and the role of the family. ${ }^{15-18}$ Another explanation for conflicting outcomes in behavioural research can be found in the sources of information: the child, the parents or other observers. Each source requires specific measurement tools and generates data from a specific viewpoint.

This study aimed to compensate for some of the shortcomings of current research by a comprehensive assessment of the psychological, behavioural and social adaptation in children and adolescents with JCA. To increase the likelihood of reliable answers, and to prevent denial of emotional problems, validated questionnaires were integrated into personal interviews with children and their parents. Skilled interviewers, familiar with chronically ill children, were trained to ensure genuine involvement. Children and adolescents with JCA were compared with healthy children and adolescents with respect to perceived competence, psychopathology and 
Table 1 Numbers of participants with $\mathcal{F} C A$ according to age, sex and onset type. Numbers of healthy participants according to age and sex

\begin{tabular}{lllllll}
\hline & & $\begin{array}{c}\text { Ages } \\
7-11\end{array}$ & $\begin{array}{l}\text { Ages } \\
12-16\end{array}$ & Girls/boys & $\begin{array}{l}\text { Ages } 7-11 \\
\text { Girls/boys }\end{array}$ & $\begin{array}{l}\text { Ages 12-16 } \\
\text { Girls/boys }\end{array}$ \\
\hline Healthy & 52 & 25 & 27 & $32 / 20$ & $14 / 11$ & $18 / 9$ \\
JCA & 47 & 23 & 24 & $32 / 15$ & $15 / 8$ & $17 / 7$ \\
Oligoarticular & 26 & 14 & 12 & $20 / 6$ & $11 / 3$ & $9 / 3$ \\
Polyarticular & 10 & 3 & 7 & $5 / 5$ & $-/ 3$ & $5 / 2$ \\
Systemic & 11 & 6 & 5 & $7 / 4$ & $4 / 2$ & $3 / 2$ \\
\hline
\end{tabular}

social functioning. As the adjustment of children and adolescents is closely related to family functioning and social support, these domains were studied as well. It was hypothesised that children and adolescents with JCA show higher rates of maladjustment than their healthy peers do.

\section{Methods}

PARTICIPANTS

Participants were 23 children (ages $7-11$ years) and 24 adolescents (ages 12-16 years) with JCA, all of them ambulatory patients of the Wilhelmina Children's Hospital in Utrecht. JCA had been diagnosed according to the criteria of the EULAR. ${ }^{19}$ All three onset types were represented: oligoarticular, polyarticular and systemic onset JCA. Twenty nine patients were free of active arthritis. Eighteen patients had active disease defined as swelling or heat and limitation of motion in at least one joint at the time of the study. A group of 25 healthy children (ages 7-11 years) and 27 healthy adolescents (ages 12-16 years) also participated in this study. Several schools in the hospital area were informed about the background and the aims of our research project. After informed consent of the school principal and the council of parents had been obtained, information about the project was presented by one of the authors to specific classes that were of an appropriate age. Boys and girls could volunteer to participate. In the final selection of volunteers, the age and sex distribution of the JCA group was taken into account. As a result, the children and adolescents with JCA were comparable in age and sex to the healthy children and adolescents (table 1).

Socioeconomic level of the families was assessed by a combination of parental occupation, education and income $\mathrm{e}^{20}$ and divided into higher, middle or lower class. There was a tendency of over-representation of the higher socioeconomic class as compared with the middle class in the group of healthy volunteers $(p=0.05)$. The percentages of families of patients and of healthy participants in the lower class were almost equal (32 and 30 respectively). Children and adolescents who were under medical attendance were excluded from the healthy control group. As to the family situation, most children and adolescents lived with both parents (participants with JCA: 41 out 47; healthy participants: 46 of 52). Two of the children and two of the adolescents with JCA attended schools for special education. The children of the three JCA onset types tended to differ with respect to sex: there were more girls with oligoarticular onset JCA $(\mathrm{p}=0.04)$. The children with polyarticular onset JCA were older at the onset of the disease (table 2, p=0.01). The children with polyarticular onset JCA tended to have a shorter illness duration (table 2, $\mathrm{p}=0.02$ ).

Permanent loss of functional abilities attributable to irreversible joint deformity was assessed by the Joint Alignment and Motion (JAM) Scale. ${ }^{21} 22$ Range of motion (ROM) was estimated for 44 joints. JAM scores 3 and 4 represent moderately and severely decreased ROM respectively, associated with irreversible joint deformity. In the group of patients with oligoarticular onset JCA, 16 patients had no permanently decreased ROM. Eight patients had a moderately decreased ROM score 3 in one to four joints, and one patient had a severely decreased ROM (score 4) in one joint. With one exception, all afflicted joints belonged to the lower extremities (hips, knees). In one girl, the disease had an oligoarticular onset, but a severe polyarticular course. She had permanent deformities in 20 joints. In the group of patients with polyarticular onset JCA, two patients had no permanently decreased ROM. Six patients had a moderately or severely decreased ROM in one to four joints, two patients in 15-18 joints. In the group of patients with systemic onset JCA, two patients had no permanently decreased ROM. Four patients had a moderately decreased ROM in one to four joints, five patients a moderately or severely decreased ROM in more than four joints. The majority of the patients with oligoarticular onset JCA had no medication. Patients with polyarticular onset JCA all used non-steroidal anti-inflammatory drugs (NSAIDs) in combination with disease modifying drugs. Patients with systemic onset JCA were treated with NSAIDs or NSAIDs in combination with low dose methotrexate.

\section{PROCEDURE}

Data were gathered by standardised questionnaires with multiple choice answers during two sessions on two consecutive days at the hospital. Between answering the questions, the children and parents could elaborate on personal subjects. This procedure had been chosen to facilitate a sense of trust. Child and parent(s) were interviewed simultaneously but separately. The answers were scored directly by the interviewer into one of several pre-specified

Table 2 Age at onset of $\mathcal{F C A}$ and disease duration for participants with $\mathcal{F C A}$ according to age and onset type: mean (SD) in years

\begin{tabular}{|c|c|c|c|c|c|c|}
\hline & Children & (Ages 7-11) & & Adolescents & (Ages 12-16) & \\
\hline & Oligoarticular & Polyarticular & Systemic & Oligoarticular & Polyarticular & Systemic \\
\hline Age at onset & $3.1(1.8)$ & $4.6(1.3)$ & $2.9(1.1)$ & $6.1(4.2)$ & $8.6(4.5)$ & $6.2(3.1)$ \\
\hline Disease duration & $6.4(1.8)$ & $4.3(1.1)$ & $6.2(1.6)$ & $7.4(4.4)$ & $5.5(3.1)$ & $7.4(3.5)$ \\
\hline Number & 14 & 3 & 6 & 12 & 7 & 5 \\
\hline
\end{tabular}


categories. In case of doubt, the interviewer verified with the child or parent whether the category was appropriate. The interviews of the child and the parent(s) followed the same schedule except for the specific parent or child topics. The parent(s) provided the demographic data of child and family and a disease history. All interviews were audiotaped with permission of children and parents.

The protocol of the study was approved by the Research and Ethics Committees of the Wilhelmina Children's Hospital. All parents and children gave informed consent.

MATERIALS

Perceived competence and self image

The perceived competence of the children was measured by the Dutch version of the Self Perception Profile for Children, CBSK. ${ }^{23}$ The CBSK has 36 items grouped in six subscales: intellectual skills, social acceptation, athletic skills, physical appearance, behaviour, and global self esteem. The theoretical range of scores for each subscale is from six to 24 . Reliability (Cronbach's $\alpha$ ) is fairly good (0.59 to 0.80$)$. The Self Perception Profile for Children has been used in many studies, including studies on chronic illness.

The perceived competence of the adolescents was measured by the Dutch version of the Self Perception Profile for Adolescents, CBS. ${ }^{24}$ The CBS has 40 items grouped in eight subscales. Six are equal to those of the CBSK. Additional scales relate to romance and friendships. Range of scores for each scale: five to 20 . The values of $\alpha$ range from 0.63 to 0.83 . The CBS has been used recently in some studies on chronic illness.

A Dutch achievement motivation test ${ }^{25}$ for adolescents, with 89 multiple choice items, was used to measure achievement-motivation and fear of failure. Range of scores: zero to 34 and zero to 14 respectively; $\alpha 0.65$ and 0.77 respectively. This test has not been used for chronically ill populations.

Body image was measured by several questions from the Chronic Illness Interview for Adolescents. ${ }^{26}$ Children and adolescents could indicate their sources of (dis)satisfaction with their physical appearance as to height, body weight, and gender characteristics on 5 point Likert scales. Separately, they rated their physical appearance on a visual analogue scale from zero (bad) to 10 (excellent).

\section{Psychopathology}

Depression was measured by the abbreviated version of a Dutch self report inventory. ${ }^{27}$ This inventory yields a final score (range: 0-9; a higher score representing more depressive characteristics). Reliability is high, with an $\alpha$ of 0.95. This test has been used mostly for children who are psychologically at risk.

The parents answered the questions of the Behaviour Problems section of the Dutch version of the Child Behaviour Checklist. ${ }^{928}$ These behaviour problems can be split into internalising (for example, anxious, withdrawn), and externalising (for example, aggressive, impulsive) behaviours. Range of scores: zero to 240 (total score), zero to 100 (internalising score), zero to 102 (externalising score). $\alpha$ (total score): 0.78. The CBCL has been used for about 10 years, and is considered to be a strong instrument to detect psychopathology. It has been used in many studies on chronic illness.

\section{Social functioning}

Parents rated their child's social relations on the Social Competence section of the Dutch version of the CBCL (range of scores: zero to $30 ; \alpha 0.86)$. The adolescents rated themselves on the Social Competence section of the Dutch version of the Youth Self Report ${ }^{29}{ }^{30}$; range of scores: zero to $23 ; \alpha 0.82)$. Questions from the Chronic Illness Interview for Adolescents ${ }^{26}$ pertained to school activities and the intensity of peer relationships, including participation in sports (on a 3 point Likert scale), number of subjects at school and frequency of seeing friends (on a 3 point Likert scale). For children, frequency of playing with friends (on a 3 point Likert scale) was assessed. Social anxiety of the children was measured with a Dutch scale, the SASK. ${ }^{31}$ This is a 46 item scale with yes/no answers on six subscales. Three subscales investigate the situation in which anxiety is felt, focusing on social skills, physical skills, and physical appearance. Two subscales measure cognitive, physiological and emotional reactions. Only the total score has been used (range: zero to $46 ; \alpha$ 0.90). One subscale measures the tendency to focus on positive answers about social adjustment, even with respect to situations where most children react with anger or distress (range of scores: zero to $10 ; \alpha 0.68$ ). The SASK has been modestly used in chronically ill populations.

\section{Family functioning}

The adolescents and all parents rated their family on the Dutch version of the FACES (GDS). ${ }^{32}$ The GDS is a family dimensions questionnaire consisting of 44 items with a 4 point scale and three subscales: cohesion, adaptation, and social desirability. Range of scores: $23-92 ; 13-52$ and 8-32 respectively, with $\alpha$ between 0.80 and 0.85 .

The parents answered questions about their attitudes towards raising children on the Parental Attitude Research InstrumentAmsterdam version. ${ }^{33}$ This is a 15 item questionnaire with a 4 point answering scale and four subscales: overprotection (range 6-23; $\alpha$ 0.67), autocratic attitude (range 4-18; $\alpha$ 0.77), autonomy enhancing attitude (range $5-19 ; \alpha 0.55$ ), and self pity (range $6-23 ; \alpha$ 0.57). The family functioning instruments have been mostly used in populations of children who are psychologically at risk.

\section{Social support}

Social support for the adolescents was measured with the Dutch Social Support List, (Dutch Institute for Mental Health, unpublished). The questionnaire assesses the amount of emotional and practical support from significant others, on 5 point Likert scales. 
Table 3 Perceived competence, self image, depression and behavioural problems of participants with $\mathcal{F} C A$ and healthy participants, with mean (SD) scores, numbers of participants and levels of statistical significance $(p)$

\begin{tabular}{|c|c|c|c|c|c|c|}
\hline & \multicolumn{3}{|c|}{ Children (ages 7-11) } & \multicolumn{3}{|c|}{ Adolescents (ages 12-16) } \\
\hline & Mean (SD) & Number & $p$ Value & Mean (SD) & Number & $p$ Value \\
\hline \multicolumn{7}{|c|}{ Global self esteem } \\
\hline JCA & $20.0(3.0)$ & 22 & \multirow[t]{2}{*}{0.84} & $15.2(4.0)$ & 23 & \multirow[t]{2}{*}{0.16} \\
\hline Healthy & $20.1(2.9)$ & 25 & & $16.6(3.0)$ & 27 & \\
\hline \multicolumn{7}{|c|}{ Athletic competence } \\
\hline JCA & $16.5(3.7)$ & 22 & \multirow[t]{2}{*}{0.03} & $10.4(4.0)$ & 23 & \multirow[t]{2}{*}{0.12} \\
\hline Healthy & $19.6(3.3)$ & 25 & & $12.9(3.1)$ & 27 & \\
\hline \multicolumn{7}{|c|}{ Achievement motivation } \\
\hline JCA & not & & & $15.6(6.8)$ & 23 & \multirow[t]{2}{*}{0.88} \\
\hline Healthy & applicable & & & $15.2(4.3)$ & 27 & \\
\hline \multicolumn{7}{|c|}{ Fear of failure } \\
\hline JCA & not & & & $8.0(3.6)$ & 23 & \multirow[t]{2}{*}{0.92} \\
\hline Healthy & applicable & & & $8.0(4.0)$ & 27 & \\
\hline \multicolumn{7}{|c|}{ Satisfaction with physical appearance } \\
\hline JCA & $7.8(1.8)$ & 23 & \multirow[t]{2}{*}{0.93} & $6.2(1.4)$ & 23 & \multirow[t]{2}{*}{0.86} \\
\hline Healthy & $7.6(1.6)$ & 25 & & $6.3(1.2)$ & 27 & \\
\hline \multicolumn{7}{|l|}{ Depression } \\
\hline JCA & $1.0(1.5)$ & 22 & \multirow{2}{*}{0.90} & $1.5(2.0)$ & 23 & \multirow[t]{2}{*}{0.83} \\
\hline Healthy & $1.3(2.0)$ & 25 & & $1.6(1.8)$ & 27 & \\
\hline \multicolumn{7}{|c|}{ Behavioural problems (total score) } \\
\hline JCA & $35.8(23.9)$ & 23 & \multirow[t]{2}{*}{0.42} & $25.5(14.8)$ & 23 & \multirow[t]{2}{*}{0.95} \\
\hline Healthy & $31.0(16.1)$ & 25 & & $26.0(17.1)$ & 27 & \\
\hline \multicolumn{7}{|c|}{ Internalising behaviour } \\
\hline JCA & $12.5(9.2)$ & 23 & \multirow[t]{2}{*}{0.21} & $10.2(7.3)$ & 23 & \multirow[t]{2}{*}{0.64} \\
\hline Healthy & $9.8(5.3)$ & 25 & & $9.3(6.4)$ & 27 & \\
\hline \multicolumn{7}{|c|}{ Externalising behaviour } \\
\hline JCA & $11.0(8.0)$ & 23 & \multirow[t]{2}{*}{0.75} & $5.6(4.7)$ & 23 & \multirow[t]{2}{*}{0.30} \\
\hline Healthy & $10.3(7.1)$ & 25 & & $7.6(6.8)$ & 27 & \\
\hline
\end{tabular}

Table 4 Social functioning (child/adolescent report) of participants with $\mathcal{F} C A$ and healthy participants, with mean (SD) scores, numbers of participants and level of statistical significance $(p)$

\begin{tabular}{|c|c|c|c|c|c|c|}
\hline & \multicolumn{3}{|c|}{ Children (ages 7-11) } & \multicolumn{3}{|c|}{ Adolescents (ages 12-16) } \\
\hline & $\begin{array}{l}\text { Mean } \\
(S D)\end{array}$ & Number & $p$ Value & $\begin{array}{l}\text { Mean } \\
(S D)\end{array}$ & Number & p Value \\
\hline \multicolumn{7}{|c|}{ Participation in sports } \\
\hline JCA & not & & & $1.4(1.0)$ & 23 & \multirow[t]{2}{*}{0.00} \\
\hline Healthy & applicable & & & $2.4(0.8)$ & 27 & \\
\hline \multicolumn{7}{|c|}{ Number of subjects at school } \\
\hline JCA & not & & & $7.4(1.2)$ & 23 & \multirow[t]{2}{*}{0.02} \\
\hline Healthy & applicable & & & $8.2(1.1)$ & 27 & \\
\hline \multicolumn{7}{|c|}{ Playing with/seeing friends } \\
\hline JCA & $1.7(0.1)$ & 23 & \multirow[t]{2}{*}{0.04} & $2.4(1.0)$ & 23 & \multirow[t]{2}{*}{0.27} \\
\hline Healthy & $2.0(0.0)$ & 25 & & $2.7(0.7)$ & 27 & \\
\hline \multicolumn{7}{|l|}{ Social anxiety } \\
\hline JCA & $8.0(7.7)$ & 23 & \multirow[t]{2}{*}{0.22} & \multicolumn{3}{|c|}{ not applicable } \\
\hline Healthy & $5.7(5.4)$ & 25 & & & & \\
\hline \multicolumn{7}{|c|}{ Focus on positive answers about social adjustment } \\
\hline JCA & $4.0(2.5)$ & 23 & \multirow[t]{2}{*}{0.01} & \multirow{2}{*}{\multicolumn{2}{|c|}{ not applicable }} & \\
\hline Healthy & $2.1(1.5)$ & 25 & & & & \\
\hline \multicolumn{7}{|l|}{ JCA } \\
\hline oligoarticular & $3.2(2.3)$ & 14 & \multirow{3}{*}{0.02} & \multirow{3}{*}{\multicolumn{2}{|c|}{ not applicable }} & \\
\hline polyarticular & omitted & 3 & & & & \\
\hline systemic & $6.0(2.5)$ & 6 & & & & \\
\hline
\end{tabular}

For parents, the Questionnaire Resources ${ }^{34}$ was used. This is a 12 item list with 5 point answering scales measuring availability of support, and the (emotional and physical) strength of the parent. Range of scores: $20-100$ and $4-20$ respectively; $\alpha$ about 0.80 . Contentment of the parents with the available support was measured on a 5 point Likert scale.

ANALYSIS

Differences between the group of participants with JCA and the group of healthy participants were analysed separately for children and adolescents. All children and adolescents were accompanied by their mother and analyses of parental data have been based upon the information given by the mother. Furthermore, comparisons have been made between the three JCA onset types. Differences were studied by means of analyses of (co)variance
(SPSS AN(C)OVA) for each variable. In these analyses, age, sex, and socioeconomic level, if appropriate, were used as covariates. For the differences between the participants with JCA and the healthy participants and the differences between the JCA onset types, mean (SD) scores will be presented, with the significance of the $F$ ratio. Because of the large number of variables, a significance level (p) of 0.01 has been chosen to report the main results. A p value between 0.01 and 0.05 is considered to indicate a trend: these results yield hypotheses for further research.

\section{Results}

PERCEIVED COMPETENCE AND SELF IMAGE

The global self esteem of the children and adolescents with JCA did not differ from the global self esteem of the healthy children and adolescents (table 3). This was also true for the several domains of self esteem, with the exception of a tendency towards a lower rating on athletic competence by children with JCA (table 3).

There were no differences between adolescents with JCA and healthy adolescents with respect to achievement-motivation and fear of failure. The children and adolescents with JCA were as satisfied with their physical appearance as were their healthy peers (table 3 ).

No differences were found in perceived competence between the three JCA onset types, or in the elements of body image as far as adolescents were concerned. Children with polyarticular onset JCA, however, tended to view themselves as thinner than children from the other two JCA onset types $(p=0.05)$.

\section{PSYCHOPATHOLOGY}

Almost none of the healthy participants or the participants with JCA showed signs of depression. There were no differences with respect to depression between the groups (table 3 ).

As to behavioural problems, there were no differences between the children or adolescents with JCA and their healthy peers, either in the total score or in the scores of the internalising and externalising behavioural domains (table 3).

No differences in any of the psychopathology measurements were found among the three JCA onset types.

SOCIAL FUNCTIONING

The mean scores for social competence, based on the parental reports indicated a similar access to friends and clubs for participants with JCA and healthy participants. The adolescents with JCA themselves reported less participation in sports and tended to take fewer subjects at school (table 4). Compared with their healthy peers, children with JCA tended to play less frequently with friends (table 4 ). The two groups of adolescents did not differ in the frequency of their spontaneous social contacts.

The children with JCA did not differ significantly from their healthy peers in the degree of anxiety they felt in social situations (table 4). However, the children with JCA showed a 
Table 5 Family functioning (parental report) and child rearing attitudes of parents of participants with $\mathcal{F C A}$ and healthy participants, with mean (SD) scores, numbers of participants and level of statistical significance $(p)$

\begin{tabular}{|c|c|c|c|c|c|c|}
\hline & \multicolumn{3}{|c|}{ Children (ages 7-11) } & \multicolumn{3}{|c|}{ Adolescents (ages 12-16) } \\
\hline & Mean (SD) & Number & $p$ Value & Mean (SD) & Number & $p$ Value \\
\hline \multicolumn{7}{|l|}{ Cohesion } \\
\hline JCA & $70.6(7.0)$ & 23 & \multirow[t]{2}{*}{0.01} & $67.2(6.6)$ & 23 & \multirow[t]{2}{*}{0.68} \\
\hline Healthy & $66.4(3.6)$ & 25 & & $68.0(5.5)$ & 27 & \\
\hline \multicolumn{7}{|l|}{ Adaptation } \\
\hline JCA & $21.2(3.2)$ & 23 & \multirow[t]{2}{*}{0.01} & $23.6(4.3)$ & 23 & \multirow[t]{2}{*}{0.39} \\
\hline Healthy & $24.0(3.7)$ & 25 & & $22.7(3.5)$ & 27 & \\
\hline \multicolumn{7}{|c|}{ Autocratic style } \\
\hline JCA & $9.4(2.8)$ & 23 & \multirow[t]{2}{*}{0.10} & $9.7(3.1)$ & 23 & \multirow[t]{2}{*}{0.29} \\
\hline Healthy & $10.7(2.8)$ & 25 & & $8.8(2.7)$ & 27 & \\
\hline \multicolumn{7}{|c|}{ Autonomy enhancing } \\
\hline JCA & $10.0(3.6)$ & 23 & \multirow[t]{2}{*}{0.22} & $11.8(3.8)$ & 23 & \multirow[t]{2}{*}{0.53} \\
\hline Healthy & $11.6(4.9)$ & 25 & & $11.1(3.8)$ & 27 & \\
\hline \multicolumn{7}{|c|}{ Overprotection } \\
\hline JCA & $8.6(2.7)$ & 23 & \multirow[t]{2}{*}{0.58} & $10.1(3.6)$ & 23 & \multirow[t]{2}{*}{0.01} \\
\hline Healthy & $9.1(3.2)$ & 25 & & $8.0(2.1)$ & 27 & \\
\hline \multicolumn{7}{|l|}{ Self pity } \\
\hline JCA & $9.8(3.5)$ & 23 & \multirow[t]{2}{*}{0.14} & $10.4(2.7)$ & 23 & \multirow[t]{2}{*}{0.26} \\
\hline Healthy & $11.6(4.6)$ & 25 & & $9.4(3.3)$ & 27 & \\
\hline
\end{tabular}

Table 6 Social support as perceived by the parents of healthy participants and participants with $\mathcal{F C A}$. The group of participants with $\mathcal{F} C A$ is divided according to onset type. Mean (SD) scores, numbers of participants and level of statistical significance ( $p)$

\begin{tabular}{|c|c|c|c|c|c|c|}
\hline \multirow[b]{2}{*}{ Parents of: } & \multicolumn{3}{|c|}{ Children (ages 7-11) } & \multicolumn{3}{|c|}{ Adolescents (ages 12-16) } \\
\hline & Mean (SD) & Number & p Value & Mean $(S D)$ & Number & $p$ Value \\
\hline \multicolumn{7}{|l|}{ Social support } \\
\hline JCA & $47.8(9.8)$ & 23 & \multirow{2}{*}{0.28} & $51.1(11.8)$ & 24 & \multirow{2}{*}{0.84} \\
\hline Healthy & $51.0(10.2)$ & 25 & & $50.6(9.1)$ & 27 & \\
\hline \multicolumn{7}{|l|}{ Personal strength } \\
\hline JCA & $15.7(2.6)$ & 23 & \multirow[t]{2}{*}{0.69} & $15.3(2.5)$ & 24 & \multirow[t]{2}{*}{0.63} \\
\hline Healthy & $16.0(2.6)$ & 25 & & $15.0(2.1)$ & 27 & \\
\hline \multicolumn{7}{|c|}{ Social support JCA } \\
\hline oligoarticular & $46.4(10.2)$ & 14 & \multirow{3}{*}{0.63} & $44.3(11.8)$ & 12 & \multirow{3}{*}{0.01} \\
\hline polyarticular & Omitted & 3 & & $55.8(2.2)$ & 7 & \\
\hline systemic & $48.8(7.9)$ & 6 & & $60.4(10.3)$ & 5 & \\
\hline \multicolumn{7}{|c|}{ Contentment with support JCA } \\
\hline oligoarticular & $2.9(0.4)$ & 14 & \multirow{3}{*}{0.94} & $2.7(0.4)$ & 12 & \multirow{3}{*}{0.05} \\
\hline polyarticular & Omitted & 3 & & $3.2(0.3)$ & 7 & \\
\hline systemic & $2.9(0.2)$ & 6 & & $3.1(0.1)$ & 5 & \\
\hline
\end{tabular}

much higher tendency to focus on positive answers about social adjustment than did the healthy children (table 4).

Children with a systemic onset JCA tended to score highest in this respect.

FAMILY FUNCTIONING

The parents of the children with JCA perceived their families as higher in cohesion and lower in adaptation, than the parents of the healthy children did (table 5). The parents of the adolescents did not report differences in this respect.

The adolescents with JCA themselves however, tended to perceive a lower cohesion in their families than did the healthy adolescents $(\mathrm{p}=0.02)$.

The child rearing attitudes of parents showed similar patterns in the groups of healthy participants and participants with JCA (table 5), except for a higher level of overprotection in the group of adolescents with JCA.

As to JCA onset type, the adolescents with polyarticular or systemic onset JCA and their parents showed a higher level of social desirability in their answers on the family dimensions test than the adolescents with oligoarticular onset JCA and their parents $(\mathrm{p}=0.01)$.

Child rearing attitudes did not differ with onset type of JCA, except that parents of children with oligoarticular onset JCA showed a tendency towards more autocratic attitudes than the parents of the children with polyarticular onset JCA $(p=0.03)$. In the parents of adolescents the reverse was seen: the parents of adolescents with oligoarticular onset JCA tended to be the least autocratic and the parents of adolescents with polyarticular onset JCA tended to be the most autocratic $(p=0.03)$.

\section{SOCIAL SUPPORT}

Levels of social support and personal strength reported by parents of participants with JCA and those of healthy participants were similar (table 6). The parents of adolescents with polyarticular or systemic onset JCA reported not only having more social support, but also tended to be more content with this support than parents of adolescents with oligoarticular onset JCA (table 6).

The adolescents with JCA got more emotional support than their healthy peers, from their mothers (mean (SD) 3.7 (1.1) v 3.0 (0.8), $\mathrm{p}=0.01)$, and from professional caretakers $(0.7$ (1.0) $v 0.04(0.2), \mathrm{p}=0.01)$, with a tendency of more support from their teachers as well (1.1 (1.0) $v 0.6$ (0.8), $\mathrm{p}=0.03)$. Compared with the adolescents with oligoarticular or polyarticular onset JCA, adolescents with systemic onset JCA received more practical support from their social environment $(p=0.01)$.

BIOBEHAVIOURAL CORRELATES

In the group of children with JCA there was a strong correlation between a longer duration of the disease and the positive feelings the children had about their physical appearance $(r=0.79, \mathrm{p}=0.001)$. A greater visibility of the disease correlated with a higher degree of social support received by the parents of the children $(r=0.60, \mathrm{p}=0.01)$. These correlates did not show up in the group of adolescents. Children with an active disease showed a higher aspiration to cope with social expectations $(r=0.65, \mathrm{p}=0.01)$.

\section{Discussion}

The most prominent conclusion from this study is that the children and adolescents with JCA cope quite well with the psychological and social sequelae of their chronic condition. They perceive themselves as being as competent as their healthy peers in the daily life tasks at school and in their social behaviour. The only exception, a tendency towards a lower perceived competence in athletic skills in children, indicates a realistic assessment of physical limitations. This realism does not interfere with the development of a positive body image. Similar findings were found in a study of 31 children aged 8 to 17 years with chronic arthritis ${ }^{35}$ : children with arthritis had realistic perceptions of their own physical capabilities. A lesser perceived athletic competence did not lead to a lowered self esteem. In our study, the children with JCA feel more positive towards their body as the illness duration is longer, indicating a growing acceptance of the disease and its consequences. 
In ill as well as healthy children and adolescents there were no signs of psychopathology or depression. Socially, patients with JCA perceived themselves as being as competent as their healthy peers, but the range of their physical and social activities tended to be smaller. During adolescence, the patients themselves indicated this restricted range more clearly than their parents did. Otherwise, there were little or no differences between patient and parent reports.

Descriptions by the parents of the children with JCA showed close families with structured roles. Adapting to changing roles inside and outside the family might be hindered by the presence of a chronically ill child. The parents of the adolescents with JCA did not report this high cohesion and low adaptability, and were more comparable to the parents of the healthy adolescents. The adolescents with JCA themselves felt less cohesion in their family than did the healthy adolescents. On the other hand, the parents of the adolescents with JCA reported a higher overprotectiveness than did the parents of the healthy adolescents. These data suggest that the chronic disease has an impact on the development of adolescent independence. The adolescent seems to need more family support while learning to be independent. Therefore, parental attitudes that indicate overprotectiveness from the perspective of families with healthy adolescents, might represent supportive attitudes of protection in families with chronically ill adolescents. Adolescents with JCA received more support from their parents, from professional helpers and probably from their teachers as well. The parents of children received more social support if the disease of their child was more visible.

A significant finding was that children with JCA were more inclined to focus on positive answers about social adjustment than were their healthy peers. This inclination, of course, might have influenced the way they answered the questions. Neither our observations during the interviews, nor the data give indications that the results were being obscured by denial of problems and emotions. By integrating validated questionnaires into personal interviews, and by using child and parent reports efforts were made to prevent this bias. The overall impression is that the children gave realistic answers. Answers that might have been influenced (for example, how many friends do you have) were corrected by detailed questions (for example, how often do you play with them). In our opinion, the inclination to emphasise positive social adjustment does not reflect a tendency of "keeping up appearances", but probably reflects a high level of aspiration to cope with social expectations. As such, this behaviour is useful in the process of psychological "survival". Higher rates of active coping in children with severe JCA have been reported before. ${ }^{36}$

As to disease severity, in $42 \%$ of our patients the disease had a mild course, with - so far-no lasting joint deformities. In $58 \%$, disease severity was moderate or severe. However, there were no signs that the more severely affected patients, generally the patients with polyarticular or systemic onset JCA, did worse in the domains of psychological and social functioning. This is in line with findings from an earlier study, ${ }^{2}$ in which disability outcome did not correlate with functional limitations.

Because of the cross sectional nature of our study, some caution is warranted regarding the global picture of positive coping without psychological or social problems. This picture does not rule out the possibility of adjustment problems at an earlier or later time. Actually, from the experience of our JCA team for comprehensive care, these problems show up intermittently in the course of the disease. In due time, about half of the patients with JCA get some psychological counselling for (arising) problems.

Why are children and adolescents with JCA not as different from their healthy peers as one might expect them to be? It is probable that they do not compare themselves permanently with their healthy peers anymore. Their world has changed and so has their frame of reference. By focusing on what they still can do, they maintain positive self esteem. The differences and similarities between the healthy and ill youngsters indicate that children and adolescents with JCA are aware of their situation, but work hard to live as normal a life as possible. The costs for living a "normal" life with a demanding chronic disease might be an excessive use of energy for normal activities. The high levels of behavioral and social adaptation ${ }^{37}$ might imply enduring psychological strain, which possibly contributes to the severity of autonomic dysregulation in JCA, as has been shown in this group of patients. ${ }^{38}$ The altered function of the autonomic nervous system is associated with changes in the response of leucocytes to mediators of the autonomic nervous system, which has negative consequences for the process of inflammation. ${ }^{38}$ These findings put the hypothesised link between stress and chronic arthritis ${ }^{39}$ in a different light. It is possible that the autonomic dysregulation represents the physiological price to pay for the high levels of behavioural and social adaptation.

The authors thank I de Graaf, J J van der Net, P J M Helders, C C E de Jong-de Vos van Steenwijk, J A Hogeweg and C J Heijnen, all of them members of the Utrecht JCA research group, for their collaboration in this study. The authors are greatly indebted to P Westers from the Centre for Biostatistics, Utrecht University, for statistical advices, and to R E Petty from Vancouver, Canada, for his overall review.

Funding: this research project was financed by the "Stichting Het Zieke Kind in Beweging" (the Foundation for Physical Fitness in Chronically Ill Children).

1 Baildam EM, Holt PJL, Conway SC, Morton MJS. The association between physical function and psychological problems in children with juvenile chronic arthritis. Br J Rheumatol 1995;34:470-7

2 Van der Net J, Prakken ABJ, Helders PJM, Ten Berge M, Van Herwaarden M, Sinnema G, et al. Correlates of disablement in polyarticular juvenile chronic arthritis - a cross-sectional study. Br J Rheumatol 1996;35:91-100.

3 Reisine ST. Arthritis and the family. Arthritis Care Res 1995;8:265-71.

4 Lustig JL, Ireys HT, Sills EM, Walsh BB. Mental health of mothers of children with juvenile rheumatoid arthritis: 5 Cadral as mediator. J Pediatr Psychol 1996;21:719-33.

Cadlnan D, Boyle M, Szatmari P, Offord DR. Chronic illness, disability and mental and social well-being: Findings of the Ontario child health study. Pediatrics 1987;
79:805-13. 
6 Gortmaker SL, Walker DK, Weitzman M, Sobol AM. Chronic conditions, socio-economic risks, and behavioral
problems in children and adolescents. Pediatrics $1990 ; 85$ : problem

7 Vandvik IH. Mental health and psychosocial functioning in children with recent onset of rheumatic disease. J Child Psychol Psychiatry 1990;31:961-71.

8 Eiser C. Psychological effects of chronic disease. J Child Psychol Psychiatry 1990;31:85-98.

9 Achenbach TM, Edelbrock CS. Manual for the child behavior checklist and revised child behavior profile. Burlington University of Vermont, 1983.

10 Hodges $\mathrm{K}$. Assessing children with a clinical research interview. The child assessment schedule. In: Prinz RJ, ed. Advances in behavioural assessment of children and families. Greenwich, CT: JAI Press, 1987:203-33.

11 Quirk ME, Young MH. The impact of JRA on children, adolescents and their families. Current research and impli-

12 Harris JA, Newcomb AF, Gewanter HL. Psychosocial effects of juvenile rheumatic disease: the family and peer systems as a context for coping. Arthritis Care Res 1991;4: systems $123-30$.

13 Timko C, Stovel KW, Moos RH, Miller JJ 3rd. Adaptation to juvenile rheumatic disease: A controlled evaluation of functional disability with a one-year follow-up. Health Psychol 1992;11:67-76.

14 Ennet ST, DeVellis BM, Earp JA, Kredich D, Warren RW, Wilhelm CL. Disease experience and psychosocial adjustment in children with juvenile rheumatoid arthritis children's versus mothers' reports. J Pediatr Psychol 1991; 16:557-68.

15 Myones BL, Williams GF, Billings A, Miller JJ 3rd. Social environment in families of children with juvenile arthritis. Arthritis Care Res 1988;1:17-22.

16 Varni JW, Wilcox KT, Hanson V. Mediating effects of family social support on child psychological adjustment in juvenile rheumatoid arthritis. Health Psychol 1988;7:421juven 31 .

17 Vandvik IH, Hoyeraal HM, Fagertun H. Chronic family difficulties and stressful life events in recent onset juvenile arthritis. J Rheumatol 1989;16:1088-92.

18 Timko C, Stovel KW, Moos RH. Functioning among mothers and fathers of children with juvenile rheumatic disease: A longitudinal study. J Pediatr Psychol 1992;17:705-24.

19 Wood PHN. Special meeting on nomenclature and classification of arthritis in children. In: Munthe E, ed. The care of rheumatic children. Basle: EULAR, 1987:47-50.

20 Central Bureau of Statistics. Standard Classification of Occupations 1992. The Hague: SDU, 1993.

21 Spiegel TM, Spiegel JS, Paulus HE. The joint alignment and motion scale: a simple measure of joint deformity in patients with rheumatoid arthritis. J Rheumatol 1987;14: 887-92.

22 Parker JW, Harrell PB, Alarcon GS. The value of the joint alignment and motion scale in rheumatoid arthritis. J Rheumatol 1988;15:1212-15.
23. Harter S. Manual for the self-perception profile for children. Denver: University of Denver, 1985.

24 Harter S. Manual for the self-perception profile for adolescents. Denver: University of Denver, 1988.

25 Hermans HJM. Prestatie motivatie test voor kinderen (Achievement motivation test for children). Handleiding (Manual). Lisse: Swets and Zeitlinger, 1983.

26 Sinnema G, Bonarius JCJ, Van der Laag H, Stoop JW. The development of independence in adolescents with cystic fibrosis. J Adolesc Health 1988;9:61-6.

27 De Wit CAM. Depressievragenlijst voor kinderen (Depression questionnaire for children). Handleiding en testmateriaal (Manual and test). Amersfoort: ACCO, 1987.

28 Verhulst FC, Koot JM, Akkerhuis GW, Veerman, JW. Praktische handleiding voor de CBCL (Manual Child Behavior Checklist). Assen/Maastricht: Van Gorcum, 1990.

29 Achenbach TM, Edelbrock C. Manual for the youth self-report and profile. Burlington: University of Vermont, 1987.

30 Verhulst FC, Prince J, Vervuurt-Poot C, De Jong J. Mental health in Dutch adolescents: Self-reported competencies and problems for ages 11-18. Acta Psychiatr Scand 1989; 80:1-48.

31 Dekking YM. Sociale angst schaal voor kinderen (Social anxiety scale for children). Handleiding (Manual). Lisse: Swets and Zeitlinger, 1983.

32 Olson DH, Portner J, Lavee Y. FACES 3: Family adaptibility and cohesion evaluation scales. [Doctoral dissertation.] St Paul: University of Minnesota, 1985.

33 De Leeuw ED. The Dutch version of the parental attitude research instrument. Amsterdam: University of Amsterdam, 1986.

34 Petersen P. Stressors, outcome dysfunction, and resources in mothers of children with handicaps. [Doctoral dissertation]. Ohoma: University of Nebraska; 1981.

35 Malleson PN, Bennett SM, Mac Kinnon M, Jespersen DK, Coutts KD, Turner SP, et al. Physical fitness and its relationship to other indices of health status in children with chronic arthritis. J Rheumatol 1996;23:1059-65.

36 Olson AL, Johansen SG, Powers LE, Pope JB, Klein RB. Cognitive coping strategies of children with chronic illness. J Dev Behav Pediatr 1993;14:217-23.

37 Vandvik IH, Hoyeraal HM. Juvenile chronic arthritis: a biobehavioral disease. Some unsolved questions. Clin Exp Rheumatol 1993;11:669-80.

38 Kuis W, De Jong-De Vos van Steenwijk CCE, Sinnema G, Kavelaars A, Prakken B, Helders PJM, et al. The autonomic nervous system and the immune system in juvenile rheumatoid arthritis. Brain Behav Immun 1996;10: 387-98.

39 Beckham JC, Gustafson DJ, May JG, Annis LV. Stress and rheumatoid arthritis: can a cognitive coping model help explain a link? Semin Arthritis Rheum 1987;17:81-9. 